American Journal of Applied Sciences 8 (10): 989-991, 2011

ISSN 1546-9239

(C) 2011 Science Publications

\title{
A Novel Technique to Perform Plating on Printed Circuit Board
}

\author{
${ }^{1}$ S. Jayapoorani, ${ }^{2}$ Dalim Kumar Ghosh and ${ }^{3}$ Azad Mohammed Shaik \\ ${ }^{1}$ Department of Electronics and Communication Engineering, \\ Sona College of Technology, Salem-636005, Tamil Nadu \\ ${ }^{2}$ Department of Mathematics, VSB Engineering College, Karur Tamil Nadu \\ ${ }^{3}$ Consultant, Corporate Development Center India, Siemens, Bangalore, Karnataka
}

\begin{abstract}
Problem statement: This research attempts to optimize the parameters for pulse plating of silver on printed circuit board. The idea here is to use pulse plating technique which is metal deposition by pulsed electrolysis method. Approach: Printed Circuit Boards (PCB) plays a major role in all communication and electronics industry. Silver is a ductile and malleable metal which has $7 \%$ higher conductivity than copper. Here the electro deposit is influenced by current density, silver concentration in the bath, applied current type. Pulse plating technique is used in double sided printed circuit board especially in the case of plated through hole technique. Here exist a necessity to do plating which will deposit a metal wall in the substrate and it will connect between the components. Results: This method of pulse plating proves that it avoids the disadvantage of rough deposition that is caused due to DC plating in PCB's. Conclusion: The surface morphology and the grain size is measured using XRD analysis and it proves that the number of pin holes is reduced.
\end{abstract}

Key words: Printed circuit board, nano structured coating, pulse plating, square wave, manufacturing process, lower frequency, electro deposit, plating thickness

\section{INTRODUCTION}

The Printed circuit market is expanding at a dramatic rate over few years. Manufacturers are exploring new technologies in the manufacturing of printed circuit boards. After the formation of holes the most important step is metallization (Bosshart, 1983). Metallization provides a conductive media between different layers of the circuit. Manufacturers are looking for uniform plating thickness (Lesban and Voncina, 2003). Pulse plating improves the local deposit propertiesand also better control of film depositon across macroscopic dimension of the substrate (Hager, 1986). The electroplating technique is especially interesting due to its low cost, high throughput and high quality of deposit (Selvakumari et al., 2009). The plating process is one of the most critical steps in the high end PCB manufacturing process (Nelissen et al., 2005). Copper is the most conventional type of metal used for plating in PCB industry. Here silver is used for plating since it enhances tarnish resistance (Puippe and Leeman, 1986). In PCB industry DC plating is the most widely used technique. DC currents will be used to deposit copper on the substrate. The phenomenon of non-even copper distribution in holes is called "Dogboning" (Yung and Romankiw, 1989). Here pulse plating technology is used. Pulse plating is similar to dc plating but it has a square wave current along with a periodic reverse current. In practical terms low direct current is the other way of achieving good distribution but the plating cycle time would be increased (Yung et al., 2003). When a pulse plating technique is used it reduces number of pin holes. Coating of the PCB is also uniform.

Typical pulse plating uses square wave currents alternating between forward and reverse. The duty cycle of the waveform depends on the forward current on-time and off-time (Yung et al., 2004). Here only square waveform is used during the plating process. An environment friendly PCB can be obtained without using lead and by using pure silver.

The main objective of this investigation is to study the effects of the pulse plating parameters by making use of silver metal on the printed circuit board.

Corresponding Author: S. Jayapoorani, Department of Electronics and Communication Engineering, Sona College of Technology, Salem-636005, Tamil Nadu Tel: 9994770017 
Am. J. Applied Sci., 8 (10): 989-991, 2011

\section{MATERIALS AND METHODS}

A double sided printed circuit board has wiring patterns on both sides of the insulating material. It is mainly used to improve the component density. A double sided PCB is taken. Necessary holes are dropped in the board by using single head manually controlled machines. Boards can be stacked so that many of them can be drilled simultaneously (Khandpur, 2005). Now it is washed with water and with sulphuric acid in order to remove the bur in the drum. PCB is now dried.

Experiment is conducted using a pulse rectifier (Dynatronix, USA Microstar pulse series 20-30-100 w/periodic reverse rectifier). The bath consists of double cyanide of potassium and silver together with a slight excess of potassium cyanide (Canning, 1982). Here the anode is pure silver $99.99 \%$ and the cathode is the printed circuit board. Here the ph value of the bath is checked using ph meter and it is 11.76. The anode and cathode size ratio is 2:1. Anode is connected to the positive terminal of the rectifier and cathode to the negative terminal of the rectifier. Other area is masked except the holes (Fig. 1).

$\mathrm{ON}$ and OFF current introduces the parameter duty cycle into the calculation. This is the ratio that the power supply is $\mathrm{ON}$ in relation to the total $\mathrm{ON}$ and $\mathrm{OFF}$ (cycle) time. The amplitude of the pulse (ON time) is called peak current (Fig. 2). Here the square wave pulses are used since they have the advantage of the extensive duty cycle range. The micro hardness and the corrosion resistance depend mainly on the deposit composition, whereas the roughness is greatly affected by the pulse parameters (Cherkaoui et al., 1988). When the duty cycle is higher the grain size is smaller. The surface roughness is minimum for higher duty cycle and lower frequency and it is maximum for lower duty cycle and lower frequency (Shanthi et al., 2010).

\section{RESULTS}

From the Table 1 it is observed that the duty cycle obtained is very high for pulse plating technique. It will lead to finer grain size of the order less than $100 \mathrm{~nm}$. From the Table 2 it is observed that the current efficiency is higher for the pulse current rather than the conventional DC current type. The specimen is tested for XRD analysis and observed from the Fig. 3 that the grain size is of the order $45 \mathrm{~nm}$. This value is obtained from the half width beam angle which is substituted in Scherer equation to obtain the result.
Table 1: Tabulation for plated through holes

\begin{tabular}{llllll}
\hline SL No & $\begin{array}{l}\text { Current } \\
\text { (Amps) }\end{array}$ & $\begin{array}{l}\text { Voltage } \\
\text { (Volts) }\end{array}$ & $\begin{array}{l}\text { Frequency } \\
\text { (Hertz) }\end{array}$ & $\begin{array}{l}\text { Time } \\
\text { (Min) }\end{array}$ & $\begin{array}{l}\text { Duty cycle } \\
(\%)\end{array}$ \\
\hline 1. & 0.1 & 2 & 25 & 6 & 77.77 \\
2. & 0.2 & 4 & 100 & 4 & 83.40 \\
\hline
\end{tabular}

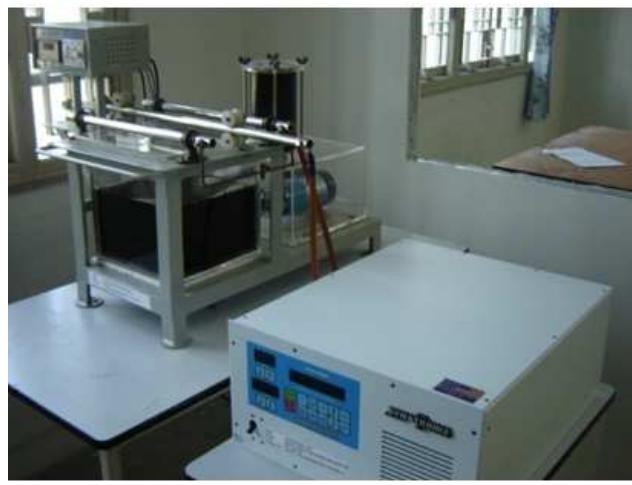

Fig. 1: Shows pulse rectifier and pulse plating set up

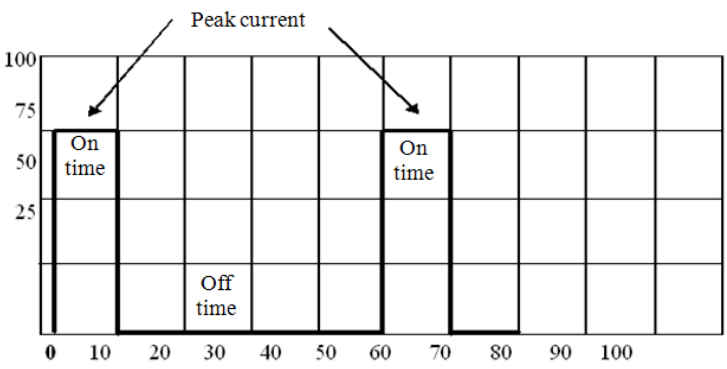

Fig. 2: Pulse current

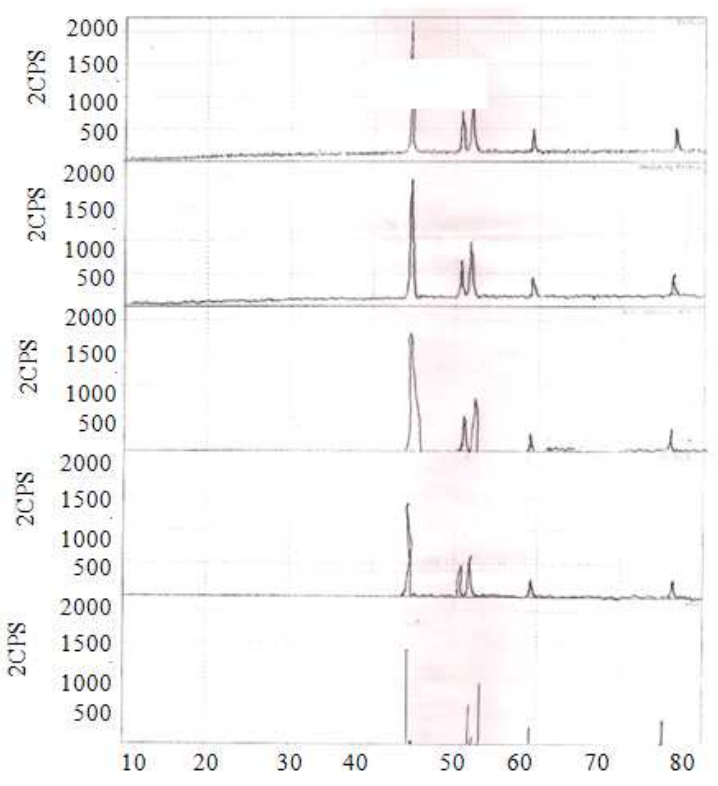

Fig. 3: XRD results 
Am. J. Applied Sci., 8 (10): 989-991, 2011

Table 2: Parameter settings for DC and pulse plating for a peak current density of $3.75 \mathrm{~A} \mathrm{dm}^{-2}$

\begin{tabular}{|c|c|c|c|c|c|c|}
\hline S. No & $\begin{array}{l}\text { Plating } \\
\text { Technique }\end{array}$ & $\begin{array}{l}\text { Theoretical } \\
\text { weight }(\mathrm{g})\end{array}$ & $\begin{array}{l}\text { Theoretical } \\
\text { Thickness }(\mu \mathrm{m})\end{array}$ & $\begin{array}{l}\text { Experimental } \\
\text { Thickness }(\mu \mathrm{m})\end{array}$ & $\begin{array}{l}\text { Weight electro } \\
\text { deposited }(\mathrm{g})\end{array}$ & $\begin{array}{l}\text { Current } \\
\text { efficiency (\%) }\end{array}$ \\
\hline 1. & DC plating & 0.0939 & 2.4995 & 2.1828 & 0.082 & 87.33 \\
\hline 2. & Pulse plating & 0.0403 & 1.0714 & 0.9849 & 0.037 & 91.93 \\
\hline
\end{tabular}

\section{DISCUSSION}

From the results obtained it is observed that the coating obtained is of nanostructured size.There will be less number of pin holes. The Result confirms that pulse. Plating is better for printed circuit boards and the parameters are optimized for pulse plating.

\section{CONCLUSION}

Pulse plating is the most recently used technique because it overcomes the disadvantages of the DC plating. Pulse plating is becoming more advantageous because it leads to smoother and fine grain deposits. Raw material consumption is low. Pulse plating reduces the variation of thickness from one part to the next. Plating speed is high and the current efficiency is also high. This process could be extended to achieve nano structured coating that finds application in the development of nanostructured coatings.

\section{REFERENCES}

Bosshart, W.C., 1983. Printed Circuit Boards: Design and Technology. 1st Edn., Tata McGraw-Hill Education, New Delhi, ISBN: 0074515497, pp: 467.

Canning, W., 1982. The Canning Handbook: Surface Finishing Technology, Integrated Design. 23rd Edn., Kluwer Academic Publishers, ISBN-10: 0419129006, pp: 1094.

Cherkaoui, M., E. Chassaing and K.V. Quang, 1988. Pulse plating of $\mathrm{Ni}-\mathrm{Cu}$ alloys. Surface Coat. Technol., 34: 243-252. DOI: 10.1016/02578972(88)90116-8

Hager, H.E., 1986. Current levelling behaviour under pulse current electroplating conditions: The role of reaction pseudocapacitance. J. Applied Electrochem., $\quad 2$ : $189-195 . \quad$ DOI: 10.1007/BF01093350
Khandpur, R.S., 2005. Printed Circuit Boards: Design, Fabrication, Assembly and Testing. 1st Edn., Tata Mc Graw-Hill Publishing Company Limited, New Delhi, ISBN: 10: 0071464204, pp: 691.

Lesban, A. and D. Voncina, 2003. Pulse current source with high dynamic. IEEE Region Comput. Tool, 2: 297-300. DOI: 10.1109/EURCON.2003.1248203

Nelissen, G. B.V.D. Bossche and L. Wanter, 2005. A performance simulation tool for bipolar pulsed PCB plating. EIMC Advanced Plating Technologies, CA.

Puippe, J.C. and F. Leeman, 1986. Theory and Practice of Pulse Plating. 1st Edn., American Electroplaters and Surfaces Finishers' Society, Orlando, Florida, pp: 247.

Shanthi, C., S. Barathan, R.M. Arunachalam and K. Karunakaran, 2010. Studies on the effect of base metal composition in pulse plating of silver over silver alloy. Int. J. Chem., 2: 14-18

Selvakumari, T.M., R.N. Emerson and S. Ganesan, 2009. Development of nanostructured stress free Pt-rich FePt films for micro electro mechanical system applications. Am. J. Applied Sci., 6: 11751179. DOI: 10.3844/ajassp.2009.1175.1179

Yung, E.K. and L.T. Romankiw, 1989. Fundamental study of acid copper through-hole electroplating process. J. Electrochem. Soc., 136: 756-767.

Yung, K.C., T.M Yue, K.C. Chan and K.F. Yeung, 2003. The effects of pulse plating parameters on copper plating distribution of microvia in PCB manufacture. IEEE Trans. Elect. Packag. Manufact., 26: 106-109. DOI: 10.1109/TEPM.2003.817722

Yung, K.C., T.M Yue, K.C. Chan and K.F. Yeung, 2004. The effect of waveform for pulse plating on copper plating distribution of microvia in PCB manufacture. Int. J. Adv. Manuf. Technol., 23: 245-248. DOI: 10.1007/s00170-003-1667-1 